\title{
BMJ Open Trends in mental health service utilisation in immigrant youth in Ontario, Canada, 1996-2012: a population-based longitudinal cohort study
}

\author{
Natasha Ruth Saunders, ${ }^{1,2,3,4,5}$ Michael Lebenbaum, ${ }^{3}$ Hong Lu, ${ }^{3}$ \\ Therese A Stukel, ${ }^{3,5}$ Marcelo Luis Urquia, ${ }^{3,5,6}$ Astrid Guttmann ${ }^{1,2,3,4,5}$
}

To cite: Saunders NR,

Lebenbaum M, Lu H, et al. Trends in mental health service utilisation in immigrant youth in Ontario, Canada, 1996-2012: a population-based longitudinal cohort study. BMJ Open 2018;8:e022647. doi:10.1136/ bmjopen-2018-022647

- Prepublication history and additional material for this paper are available online. To view please visit the journal (http:// dx.doi.org/10.1136/bmjopen2018-022647).

Received 27 February 2018 Revised 26 May 2018 Accepted 23 July 2018

Check for updates

(C) Author(s) (or their employer(s)) 2018. Re-use permitted under CC BY-NC. No commercial re-use. See rights and permissions. Published by BMJ.

For numbered affiliations see end of article.

Correspondence to Dr Natasha Ruth Saunders; natasha.saunders@sickkids.ca

\section{ABSTRACT}

Objective To describe trends in mental health service use of youth by immigration status and characteristics.

Design Population-based longitudinal cohort study from 1996 to 2012 using linked health and administrative datasets.

Setting Ontario, Canada.

Participants Youth 10-24 years, living in Ontario, Canada. Exposure The main exposure was immigration status (recent immigrants vs long-term residents). Secondary exposures were region of origin and refugee status. Main outcome measure Mental health hospitalisations, emergency department (ED) visits and outpatient visits within consecutive 3-year time periods. Poisson regression models estimated rate ratios (RR).

Results Over 2.5 million person years per period were included. Rates of recent immigrant mental health service utilisation were at least $40 \%$ lower than longterm residents $(p<0.0001)$. Mental health hospitalisation and $E D$ visit rates increased in long-term residents (hospitalisations, RR 1.09 (95\% Cl 1.08 to 1.09); ED visits, RR 1.15 (1.14 to 1.15)) and recent immigrants (hospitalisations RR 1.05 (1.03 to 1.07); ED visits, RR 1.08 (1.05 to 1.11)). Mental health outpatient visit rates increased in long-term residents (RR 1.03 (1.03 to 1.03)) but declined in recent immigrant (RR 0.94 (0.93 to 0.95)). Comparable divergent trends in acute care and outpatient service use were observed among refugees and across most regions of origin. Recent immigrant acute care use was driven by longer-term refugees (hospitalisations RR 1.12 (1.03 to 1.21); ED visits RR 1.11 (1.02 to 1.20)). Conclusions Mental health service utilisation was lower among recent immigrants than long-term residents. While acute care use is increasing at a faster rate among longterm residents than recent immigrants, the decrease in outpatient mental health visits in immigrants highlights a potential emerging disparity in access to preventative care.

\section{INTRODUCTION}

Mental health problems among youth contribute to significant morbidity and mortality across the globe, affecting one in

\section{Strengths and limitations of this study}

- This is first population-based study to evaluate trends over time in mental health service use in immigrant youth in Canada and the largest such study globally.

- Using individual linked health and demographic databases, we were able to obtain health services use for a broad range of mental health disorders in a large population of youth.

- The immigration database allowed a detailed level of information about immigration characteristics and is also distinguished from other mental health studies among immigrants which are often survey-based, self-reported (and therefore under-reported) and have smaller sample sizes.

- Limitations include absence of information on mental health need, social support and informal use of mental health services (eg, religious leaders, social workers, community support networks).

- Data on psychologist, social work and community mental health agency use are not currently available for linking.

five individuals. ${ }^{12}$ Recent population-based data suggest that the burden of mental health problems among youth in Ontario, Canada is rising, ${ }^{1}$ as is mental health service use in North America. ${ }^{3}{ }^{4}$ Understanding trends over time in the utilisation of mental health services is critical for optimal health service delivery. Accordingly, to make appropriately targeted health system improvements, identifying mental health trends in at-risk populations, including the growing population of immigrant youth, is important. This is increasingly becoming essential on an international scale given global migration and the current refugee crisis. Immigrants may face challenges integrating premigration social, cultural and political experiences and 
postmigration resettlement stressors with their new lives as permanent residents or naturalised citizens. These experiences influence the complex set of factors that shape an immigrant's ability to access health services and their risk for mental health and addiction problems before, on and after arrival. ${ }^{5-7}$

In Canada, approximately $21.9 \%$ of the population are 'permanent residents' (i.e. landed immigrants) (granted permission to live and work in Canada without limitations on one's stay). Of these, $85 \%-90 \%$ come as family class (family sponsorship) or economic class immigrants (skilled and educated workers), arriving as non-refugees. ${ }^{8}$ Over the past two decades, shifts in immigration patterns to Canada have occurred. In particular, in recent years, there has been a relative increase in migration of South and East Asian populations with a simultaneous decline in immigrants from Eastern Europe and Central Asia. ${ }^{8}$ These shifts are, in part, reflective of changes to Canadian immigration policy over time ${ }^{910}$ and indicative of changing drivers of global migration including political instability, economic opportunity and family reunification. Changes to preimmigration and postimmigration exposures that may influence mental health service need, utilisation and access may accompany these variations in migration.

Existing literature on the epidemiology of mental health problems in immigrant youth is inconsistent and typically based on smaller subsets of immigrants, most of which, rely on self-report. ${ }^{5611-13}$ Social deprivation, common among immigrants, is often cited as a risk factor for mental health problems ${ }^{14}{ }^{15}$ but protective immigration factors may counter this risk. ${ }^{16}$ One Danish population-based, administrative database study $^{17}$ showed higher rates of mental health problems in immigrants compared with non-immigrants. This is in contrast to other population-based North American and other European studies in both adolescents and adults where there is a more pronounced 'healthy immigrant effect' - that is, individuals arrive in better health, with lower rates of mental health problems, than their native-born counterparts. ${ }^{71819}$ This may be due to differences in immigration policies in receiving countries that select for healthier, more able-bodied individuals. Literature on the mental health of immigrant youth in Canada is limited to a few small survey studies that suggest lower rates of mental health problems among immigrants. ${ }^{20} 21$

Despite the substantial proportion of health services concentrated on mental healthcare and Canada's large and evolving immigrant population, little is known about the how mental health service use has changed over time in immigrants. In this study, we aimed to describe the time trends in mental health service utilisation in recent immigrant youth in Ontario compared with long-term residents. We also sought to describe these time trends among subgroups of immigrants, including by immigrant class, duration of residency in Canada and region of origin. We hypothesised that overall, immigrants would have lower utilisation of the healthcare system for mental health compared with long-term residents. However, we expected increasing rates of use in both recent and longterm residents given widespread efforts in more recent years to reduce mental health stigma and improve helpseeking behaviours. ${ }^{22}$ We hypothesise that refugees, in particular, would have an increasing trend in mental health use given the changes over time in Canada's immigration policies that have shifted refugee selection to more at-risk populations. ${ }^{910}$

\section{METHODS}

\section{Study design}

This was a population-based longitudinal study using data available through a research agreement between the Ontario Ministry of Health and Long-Term Care and the Institute for Clinical Evaluative Sciences (ICES).

\section{Patient involvement}

Patients were not directly involved in this study.

\section{Data collection}

Youth were identified using a unique, encoded, health identification number that linked several health and administrative databases available at ICES to obtain study data. Immigrant status was ascertained through the Ontario portion of the Immigration, Refugees and Citizenship Canada (IRCC) Permanent Resident Database. The IRCC database contains individual level demographic information from Ontario's permanent residents from 1985 to $2012 .{ }^{918}$ A number of immigration characteristics were used from the database including immigrant visa class (refugee vs non-refugee), duration of residence in Canada (based on the earlier of year of obtaining permanent residency in Canada or the year of Ontario Health Insurance Plan (OHIP) eligibility) and World Bank region of origin (based on the country of birth). The Registered Persons Database, Ontario's universal health insurance registry, was used to obtain age and sex for every OHIP eligible individual meeting study criteria. Emergency department (ED) visits were obtained through the National Ambulatory Care Reporting System (NACRS) (2002-2012) and hospital admissions were identified from the Canadian Institute for Health Information Discharge Abstract Database (CIHI-DAD) (1996-2012) and from the Ontario Mental Health Reporting System (OMHRS) (2005-2012). To determine outpatient service use to physicians, mental health visits to primary care physicians and psychiatrist outpatient visits were determined from the OHIP billings database (1996-2012). In Ontario, residents are eligible for most hospital and physician services through OHIP which acts as a single payer for the province. Immigrants with permanent resident status are eligible if they have resided in Ontario for 3 months. Refugees with permanent resident status may obtain OHIP coverage on arrival. ${ }^{23}$ Data from asylumseekers (those arriving in Canada and subsequently seeking refugee status) are not captured in the available 
databases. Statistics Canada's Postal Code Conversion File was used to link patients' postal code at the time of the visit to derive area level neighbourhood income quintile and community size from the 1996, 2001 and 2006 Canadian Censuses.

\section{Study population}

All youth aged 10-24 years who were eligible for OHIP during the study period from 1996 to 2012 were included. Cohorts were grouped into 3-year periods, except for the final two study years, which were grouped as a 2-year period. Youth entered the study on their 10th birthday and exited on their 25th birthday. Those with an invalid encoded health number or missing sex were excluded from the study. Non-Ontario residents at the onset of the study cohort period were also excluded. Finally, individuals without an IRCC record (Canadian-born or immigrants who moved to Ontario from another province) who first became eligible for OHIP within 5 years of each cohort period were excluded to reduce the possibility of unlinked IRCC records inappropriately being included as Canadian-born.

\section{Exposure variables}

The main exposure was immigrant status, categorised as recent immigrant or long-term resident. Recent immigrants were defined based on having an IRCC Permanent Resident Database record and a duration of residence in Ontario $<10$ years. Long-term residents included all Canadian-born Ontario residents and individuals with an IRCC Permanent Resident Database record who had landed in Canada $\geq 10$ years from the start of the cohort period. Immigrant status was determined at the beginning of each period. Thus, recent immigrants in one period could become long-term residents in a subsequent period, so long as they maintained OHIP eligibility and study age criteria.

\section{Covariates}

A number of covariates were considered in the analysis. These included age, sex, neighbourhood income quintile within a dissemination area and community size. Within recent immigrants, covariates also included refugee status, duration of residency in Ontario $(<5$ years and $\geq 5-10$ years), region of origin based on modified World Bank Regions $^{24}$ and the interaction between duration of residency and refugee status and between time with refugee status, duration of residency and region of birth.

\section{Outcome measures}

The main outcome measure was mental health service utilisation, within each time period. Utilisation was measured as all outpatient physician visits, ED visits and hospitalisations for a mental health related problem. Outpatient physician mental health visits were identified using OHIP billing codes and included visits to psychiatrists and visits to family physicians or paediatricians where billing codes for mental health services or visits with a mental health diagnostic code were used. This definition was based on a validated algorithm for ambulatory mental healthcare modified by adding specific paediatric diagnostic codes. ${ }^{25}$ These billings do not include services provided by psychologists, social workers and community-based non-physician mental health services. ED visits were identified within NACRS where the main ED diagnosis was a mental health disorder (F04-F99) or a secondary diagnosis was for self-inflicted injury (intentional self-harm, X60-X84), both based on International Classification of Disease 9th and 10th edition codes. Similarly, hospitalisations were identified as any hospitalisation with a mental health diagnostic code (F04-F99) captured in CIHI-DAD or any hospitalisation to a provincially designated mental health hospital bed identified within OMHRS, except for admissions for dementia. See online supplementary appendix A for codes used to identify mental health visits.

\section{Analysis}

The total number of individuals, person years of exposure and number and rate of events for each cohort period were estimated. An unadjusted time trend for each outcome by immigrant status was estimated. The interaction between immigrant status and time was tested and where significant, separate slopes for each exposure group were presented. A subgroup analysis on recent immigrants was then performed to estimate an adjusted time trend for recent immigrant subgroups by region of origin, refugee status and duration of residence. The unit of analysis was the individual resident. Multivariable models were built for each outcome, adjusting for age, sex, income quintile and community size. All analyses were estimated using Poisson regression with generalised estimating equations using an independent correlation structure for outpatient and ED visits and autoregressive correlation structure for hospitalisations. Results are presented as rate ratios (RR). Analyses were conducted with SAS Enterprise Guide, V.6.1 (SAS Institute, Cary, North Carolina, USA).

\section{RESULTS}

Approximately 2.5-2.9million individuals contributed to each time period. Online supplementary figure 1 shows a flow chart of a sample of a cohort period with exclusions applied. Recent immigrants made up $9.8 \%-11.5 \%$ of the cohort in each cohort period and refugees represented $17.7 \%-18.0 \%$ of recent immigrants. The regions of origin changed over time, initially with Europe and Central Asia as the leading regions and more recently South and East Asia (table 1).

Figure 1 shows the unadjusted time trends in rates of mental health service utilisation in recent immigrants and long-term residents. Mental health service utilisation was much lower for outpatient physician and acute care services in recent immigrants compared with long-term residents (all $\mathrm{RR} \leq 0.60, \mathrm{p}<0.001$ ) (table 2). Both ED visits and hospitalisation rates increased over time in recent immigrants and long-term residents but the increase in rates was higher in long-term residents (table 2). Rates of outpatient physician 
Table 1 OHIP eligible youth by period in Ontario

\begin{tabular}{lllllll} 
& 1996-1998 & 1999-2001 & 2002-2004 & 2005-2007 & 2008-2010 & 2011-2012 \\
\hline Overall, N & 2521439 & 2692524 & 2824820 & 2929879 & 2887553 & 2714188
\end{tabular}

Immigrant status, \%

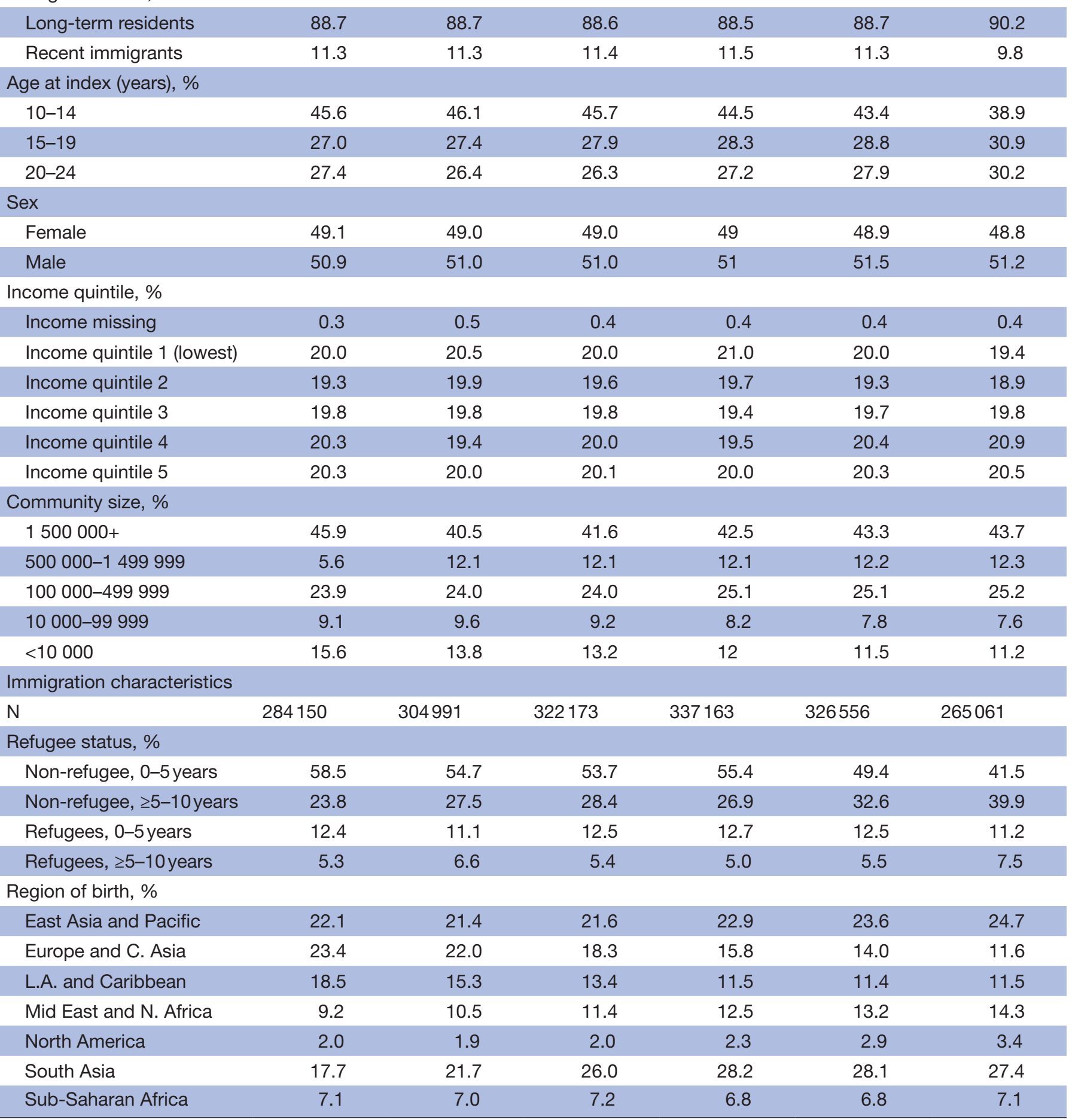

OHIP, Ontario Health Insurance Plan.

visits for mental health increased over time in long-term residents but decreased over time in recent immigrants (table 2). Low income and female sex were associated with an increased rate of mental health service use. Late childhood and early adolescence were associated with a lower rate of mental health service use. Urban individuals had the lowest rate of being admitted to hospital and the highest rate of using outpatient physician mental health services.

Within subgroups of immigrants, refugees had higher rates of $\mathrm{ED}$ visits and hospitalisations compared with 

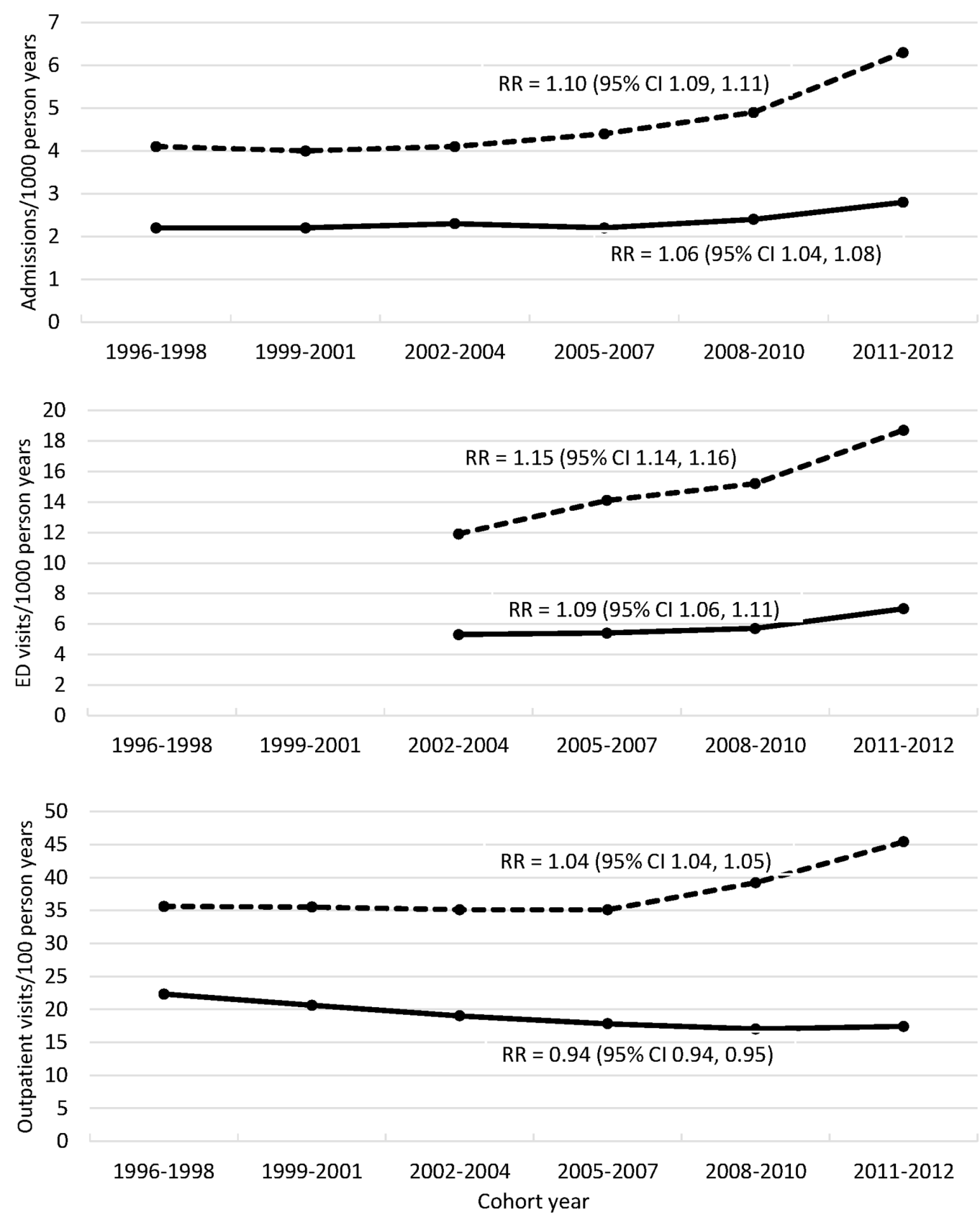

-•- Long-term resident

Recent immigrant

Figure 1 Acute care and outpatient physician visits for mental health problems over time by time period in recent immigrants and long-term residents. ED, emergency department; RR, rate ratio.

non-refugee recent immigrants and the recent increase in ED service use was driven by refugees (figure 2, table 3). The increase in hospitalisation rates for mental health was influenced primarily by refugees with a duration of residence of 5-10 years in Canada (table 3). Trends in outpatient physician visit rates among recent immigrants were similar by refugee status and duration of residence in Canada (figure 2, table 3).

The unadjusted rates of mental health outpatient and ED visits and hospitalisations by region of origin are shown in figure 3 with adjusted rates in table 3. Across all regions, except Europe, Central Asia and North America, there were convergent trends in outpatient and acute care service use for mental health conditions, with outpatient service use declining and acute care service use increasing over time.

\section{DISCUSSION}

This large population-based longitudinal study examined mental health service use over time in recent immigrants and long-term residents in Ontario. Patterns of mental health service use over time were consistently lower for outpatient physician and acute care mental health services 
Table 2 Multivariable Poisson regression models for rates of mental health hospitalisations, emergency department visits and outpatient physician visits by immigration status and over time

\begin{tabular}{|c|c|c|c|}
\hline & Hospitalisations & $\begin{array}{l}\text { Emergency department } \\
\text { visits }\end{array}$ & $\begin{array}{l}\text { Outpatient physician } \\
\text { visits }\end{array}$ \\
\hline Parameter & RR $(95 \%$ Cl) & RR $(95 \% \mathrm{Cl})$ & RR $(95 \%$ Cl) \\
\hline \multicolumn{4}{|c|}{ Immigration status (Reference: long-term residents) } \\
\hline Recent immigrants & 0.60 (0.56 to 0.64$)$ & 0.49 (0.47 to 0.52$)$ & 0.60 (0.59 to 0.61$)$ \\
\hline \multicolumn{4}{|c|}{$\begin{array}{l}\text { Relative change per time period (Reference period 1996-1998 for hospitalisations and outpatient visits, 2002-2004 for } \\
\text { emergency department visits) }\end{array}$} \\
\hline Time trend-recent immigrant & 1.05 (1.03 to 1.07$)$ & $1.08(1.05$ to 1.11$)$ & 0.94 (0.93 to 0.95$)$ \\
\hline Time trend-long-term resident & 1.09 (1.08 to 1.09$)$ & $1.15(1.14$ to 1.15$)$ & 1.03 (1.03 to 1.03$)$ \\
\hline \multicolumn{4}{|l|}{ Sex (Reference: female) } \\
\hline Male & 0.89 (0.87 to 0.91$)$ & 0.80 (0.79 to 0.82$)$ & 0.85 (0.84 to 0.85$)$ \\
\hline \multicolumn{4}{|l|}{ Age (Reference: $20-24$ years) } \\
\hline Age: $10-14$ years & $0.52(0.51$ to 0.53$)$ & $0.43(0.43$ to 0.44$)$ & 0.49 (0.48 to 0.49$)$ \\
\hline Age: $15-19$ years & 0.99 (0.98 to 1.01$)$ & 1.11 (1.09 to 1.12$)$ & $0.75(0.74$ to 0.75$)$ \\
\hline \multicolumn{4}{|l|}{ Income (Reference quintile 5) } \\
\hline Income missing & 1.98 (1.78 to 2.21$)$ & 2.12 (1.97 to 2.29$)$ & 1.05 (0.99 to 1.12$)$ \\
\hline Income quintile 1 (lowest) & 1.36 (1.32 to 1.40$)$ & $1.62(1.59$ to 1.65$)$ & 1.03 (1.02 to 1.04$)$ \\
\hline Income quintile 2 & 1.19 (1.16 to 1.22$)$ & $1.32(1.30$ to 1.35$)$ & 0.95 (0.94 to 0.96$)$ \\
\hline Income quintile 3 & 1.08 (1.05 to 1.11$)$ & $1.16(1.13$ to 1.18$)$ & 0.91 (0.90 to 0.92$)$ \\
\hline Income quintile 4 & 1.04 (1.01 to 1.07$)$ & 1.07 (1.05 to 1.09$)$ & 0.90 (0.89 to 0.91$)$ \\
\hline \multicolumn{4}{|c|}{ Community size (Reference: 1500 000+) } \\
\hline 500 000-1 499999 & 0.95 (0.92 to 0.99$)$ & 1.46 (1.42 to 1.50$)$ & 1.09 (1.08 to 1.10$)$ \\
\hline $100000-499999$ & 1.33 (1.30 to 1.36$)$ & 1.60 (1.57 to 1.63$)$ & 1.03 (1.03 to 1.04$)$ \\
\hline $10000-99999$ & 1.55 (1.50 to 1.60$)$ & 1.98 (1.94 to 2.03$)$ & 0.94 (0.93 to 0.96$)$ \\
\hline$<10000$ & 1.23 (1.19 to 1.27$)$ & 1.81 (1.77 to 1.84$)$ & 0.74 (0.74 to 0.76$)$ \\
\hline
\end{tabular}

RR adjusted for immigration status, time, sex, age, neighbourhood income quintile and community size.

$\mathrm{RR}$, rate ratios.

by recent immigrants compared with long-term residents. Rates of acute care mental health service use increased over time in both groups but at a faster rate in long-term residents. Strikingly, outpatient physician mental health service use increased over time in long-term residents but decreased in recent immigrant groups. These discordant trends in outpatient and acute care mental health service use were observed across both refugees and non-refugee immigrants and in immigrants from most world regions.

Lower rates of mental health services use by immigrants have also been observed in other large population-based cross-sectional studies of Canadian adults ${ }^{18} 26$ and in smaller cohort studies across the globe, ${ }^{27}$ though not consistently ${ }^{17}{ }^{28}$ For example, adolescents living in Sweden with foreign-born parents were less likely than adolescents with Swedish parents to use both outpatient and inpatient psychiatric services. This was particularly true for those whose families originated in low-income or middle-income countries. ${ }^{19}$ Refugees in Denmark have lower rates of psychiatric service contacts compared with their native-born peers. ${ }^{29}$ The variability in reported differences between mental health burden in immigrant and native populations may be due to differences in immigration policies in receiving countries. Some have attributed better mental health in immigrant populations to selective migration for healthier individuals. ${ }^{30} 31$ This 'healthy immigrant effect' has been observed for a number of adult conditions ${ }^{32}$ but for few paediatric diseases $^{33} 34$ and, to our knowledge, has not been demonstrated in Canadian refugee youth. Lower rates of mental health service use may be due to different care-seeking behaviours, with poor self-identification of mental health problems or more internalising problems in immigrant populations. ${ }^{20} 27$

In both recent immigrants and long-term residents, we found increases in ED visits and hospitalisations over time. Similar trends among youth have been reported in the $\mathrm{USA}^{3}$ and Australia. ${ }^{35}$ This may be a reflection of greater awareness and acceptance of mental health problems in recent years from reduced stigma ${ }^{22}$ or formal strategies to improve access to mental health services in the last several years in Ontario. ${ }^{36}{ }^{37}$ The differential rates of increase in acute care service use in these populations may be that strategies to improve mental health services and reduce 

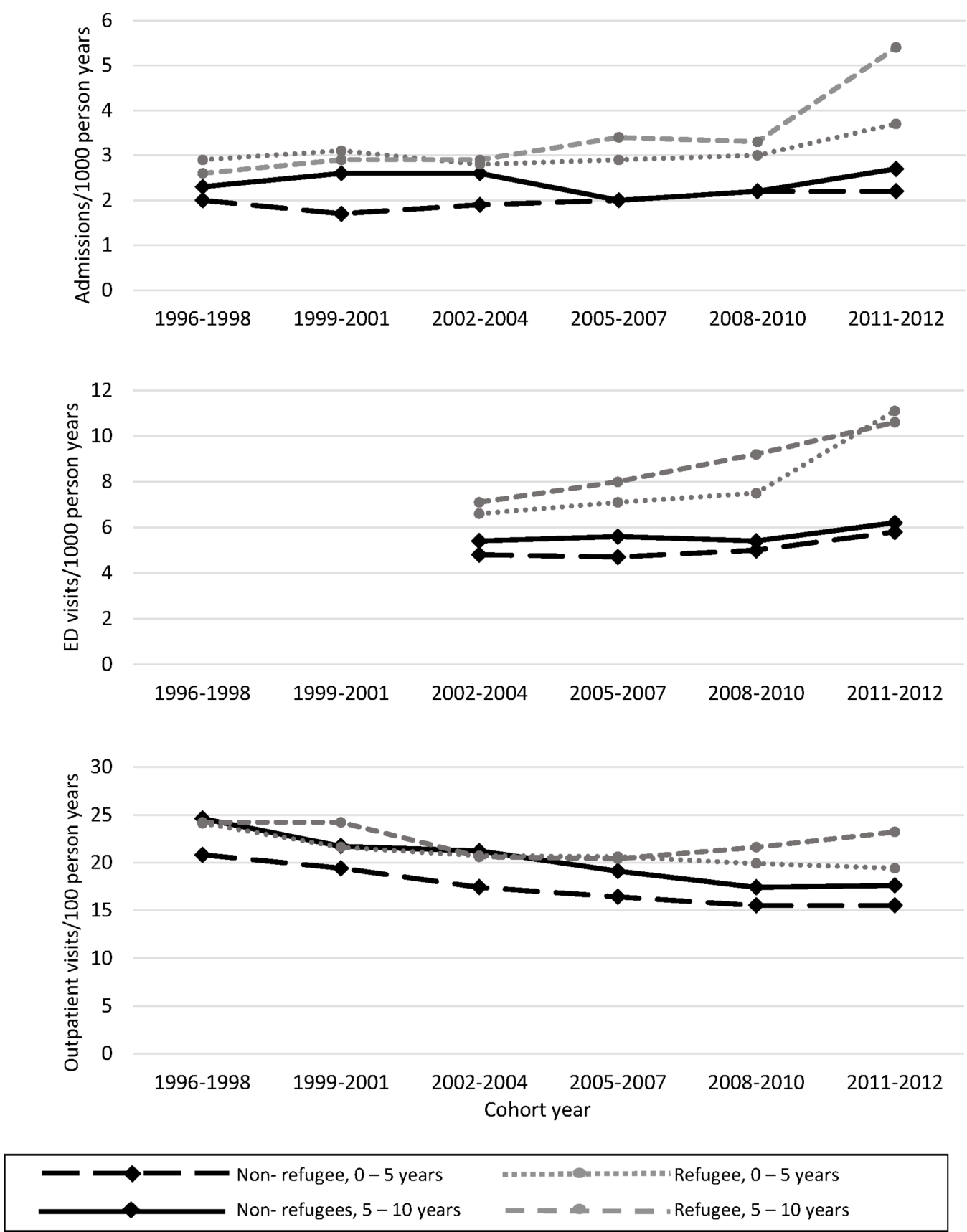

Figure 2 Acute care and outpatient visits for mental health problems over time by time period by immigration class and recency of immigration. ED, emergency department.

mental health stigma are not reaching all populations, in particular recent immigrant youth. The increasing rate over time in acute care service use by refugees highlights the importance of the vulnerability of this population and the need for active surveillance of individuals, especially with the current global refugee crisis and changes to immigration policies that select for a larger number of more vulnerable refugees. ${ }^{9}$

The divergent trends in outpatient physician service use over time between study groups signals emerging differences in health service delivery for recent immigrants. This may be a reflection of different access to or availability of outpatient physician care or increasing stigma of mild mental health problems among immigrants with consequent internalisation of mental health problems. Moreover, there may be a lack of familiarity with mental health services in certain immigrant populations. For example, while Swedish immigrant youth have lower rates of mental health utilisation compared with non-immigrants ${ }^{19}$ their rates of self-reported, parent-reported and teacher-reported mental health problems are similar to non-immigrants, ${ }^{28}$ suggesting a potential unmet need in service delivery. Similarly, despite high rates of mental distress, refugee children in Denmark use fewer psychiatric services and therefore may experience barriers to access and care for mental health. ${ }^{29}$ 
Table 3 Multivariable Poisson regression models for time trends in mental health hospitalisations, emergency department visits and outpatient physician visits within recent immigrant groups

\begin{tabular}{|c|c|c|c|}
\hline & Hospitalisations & Emergency department visits & Outpatient physician visits \\
\hline Parameter & RR $(95 \% \mathrm{Cl})$ & RR $(95 \% \mathrm{Cl})$ & RR $(95 \% \mathrm{Cl})$ \\
\hline \multicolumn{4}{|l|}{ Immigration class } \\
\hline Non-refugees, 0-5years & 1.04 (1.01 to 1.07$)$ & 1.04 (1.00 to 1.07$)$ & 0.93 (0.92 to 0.94$)$ \\
\hline Non-refugees, $\geq 5-10$ years & 1.01 (0.97 to 1.05$)$ & 1.05 (1.01 to 1.10$)$ & 0.93 (0.92 to 0.94$)$ \\
\hline Refugees, $0-5$ years & $1.02(0.97$ to 1.08$)$ & 1.14 (1.07 to 1.22$)$ & 0.95 (0.93 to 0.96$)$ \\
\hline Refugees, $\geq 5-10$ years & $1.12(1.03$ to 1.21$)$ & 1.11 (1.02 to 1.20$)$ & 0.95 (0.93 to 0.97$)$ \\
\hline \multicolumn{4}{|l|}{ Region of origin } \\
\hline East Asia and Pacific & $1.02(0.97$ to 1.07$)$ & 1.10 (1.04 to 1.17$)$ & 0.93 (0.92 to 0.94$)$ \\
\hline South Asia & $1.05(1.00$ to 1.11$)$ & 1.08 (1.02 to 1.14$)$ & $0.92(0.91$ to 0.94$)$ \\
\hline Sub-Saharan Africa & $1.04(0.97$ to 1.11$)$ & 1.10 (1.00 to 1.20$)$ & 0.89 (0.87 to 0.91$)$ \\
\hline Middle East and North Africa & 0.98 (0.91 to 1.05$)$ & 1.05 (0.98 to 1.11$)$ & 0.96 (0.94 to 0.98$)$ \\
\hline Latin America and Caribbean & 1.08 (1.03 to 1.13$)$ & 1.12 (1.06 to 1.18$)$ & 0.95 (0.94 to 0.97$)$ \\
\hline Europe and Central Asia & $1.17(1.11$ to 1.24$)$ & 1.16 (1.10 to 1.22$)$ & 1.01 (0.99 to 1.03$)$ \\
\hline North America & $1.00(0.89$ to 1.14$)$ & 0.92 (0.76 to 1.13$)$ & $0.96(0.91$ to 1.01$)$ \\
\hline Long-term residents & 1.09 (1.08 to 1.09$)$ & 1.15 (1.14 to 1.15$)$ & 1.03 (1.03 to 1.03$)$ \\
\hline
\end{tabular}

RRs for immigration class adjusted for immigration class, time, sex, age, neighbourhood income quintile and community size. RRs for region of origin adjusted for region of origin, time, sex, age, neighbourhood income quintile and community size.

All RRs are for the relative change per time period within each group (Reference period 1996-1998 for hospitalisations and outpatients visits, 2002-2004 for emergency department visits).

$\mathrm{RR}$, rate ratios.

Conversely, these findings may signify that immigrants are increasingly receiving alternative, non-physician mental health services though school-based programmes, community mental health service agencies or psychologists. The observed regional differences in outpatient trends, with 'Western' regions having more similar trends to long-term Canadian residents, suggests that cultural congruency may be contributing to the observed findings. Equally, the observed differences may be explained by a heavier reliance on informal supports from strong familial and social networks in immigrant populations. ${ }^{38}$ This latter notion could enhance strategies to improve the mental health of high use populations, including those who are native-born.

\section{Strengths and limitations}

To our knowledge, this is the first study to evaluate trends over time in mental health service use in immigrant youth in Canada and the largest such study globally. Using individual linked health and demographic databases, we were able to obtain health services use for a broad range of mental health disorders in a large population of youth. We had almost complete provincial data with virtually no loss of individual records. The immigration database allowed a detailed level of information about immigration characteristics. This study is also distinguished from other mental health studies among immigrants which are often survey-based, self-reported (and therefore under-reported), have smaller sample sizes and are largely focused on adults.
Limitations to this study include absence of information on mental health need, social support and informal use of mental health services (eg, religious leaders, social workers, community support networks). Data on psychologist, social work and community mental health agency use are not currently available for linking. These data would help contextualise our findings and allow us to understand whether observed divergent trends are related to difficulty accessing physician care or rather, determine if there are differential treatment-seeking behaviours by recent immigrants. Our definition of mental health hospitalisation did not include the small number of hospitalisations for self-injury where there may have been coexisting mental illness but the injury itself was the diagnosis most responsible for the length of stay. Our study did not include measures of clinical comorbidities which may affect mental health service use. We did not have available primary care data from community health centres which traditionally serve a higher proportion of immigrants and marginalised populations. ${ }^{39}$ However, community health centres in Ontario serve less than $1 \%$ of the population, of which $16 \%$ are newcomers. ${ }^{39}$ In this study, we were not able to track immigrants who entered Ontario from a different province, refugee claimants awaiting a decision on residency, temporary residents or 'non-status' residents. Finally, differential self-perceived mental health status and cultural incongruence may lead to misdiagnosis and therefore under-reporting of mental health problems, by healthcare providers. 
East Asia and Pacific

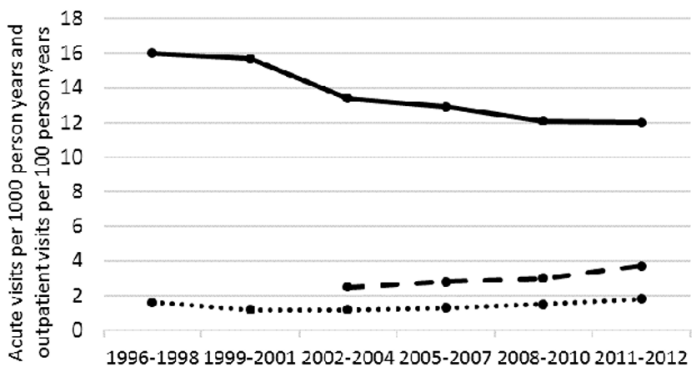

Sub-Saharan Africa
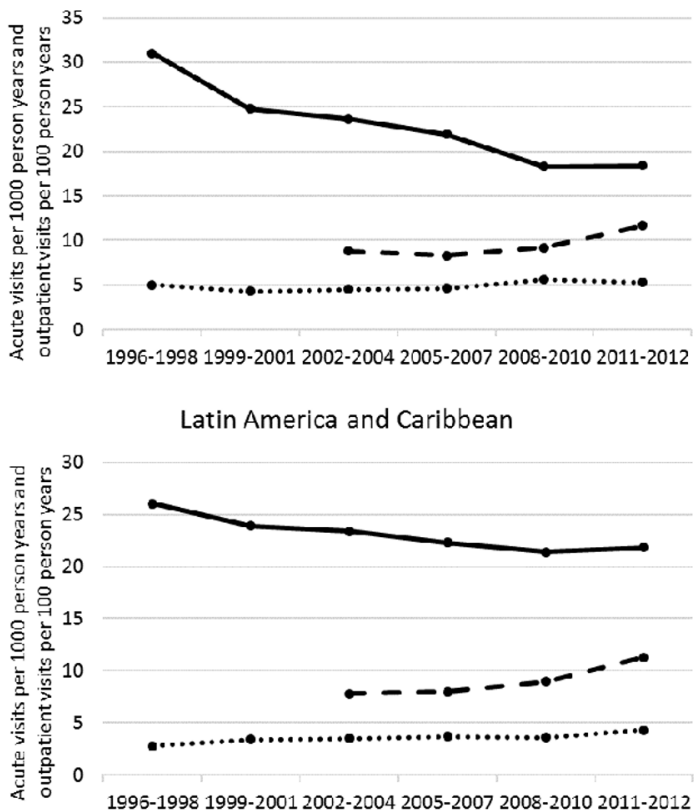

North America

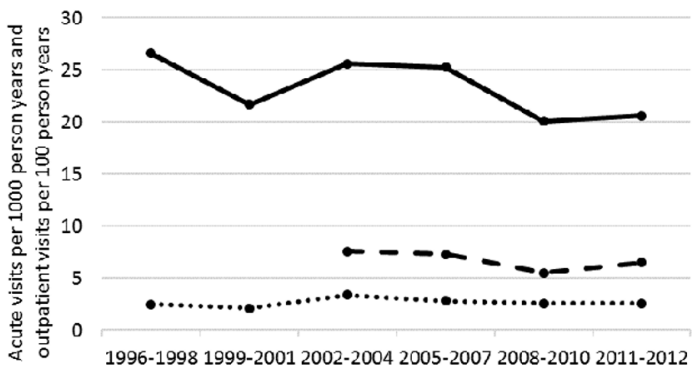

South Asia

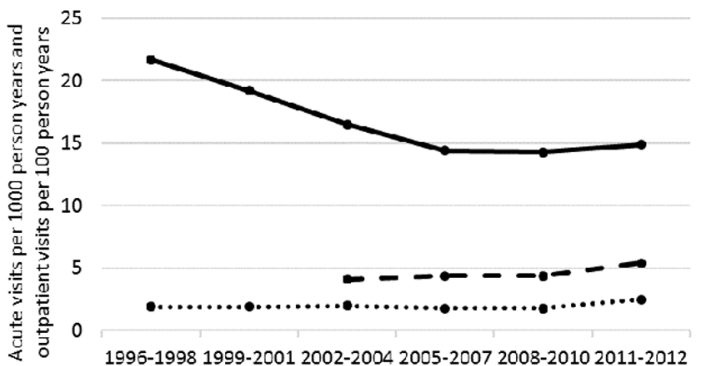

Middle East and North Africa

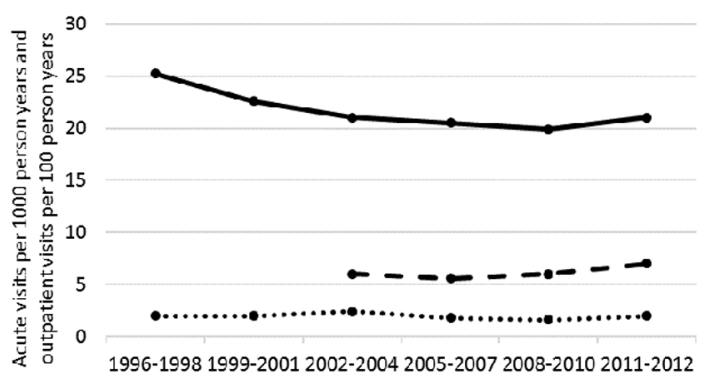

Europe and Central Asia

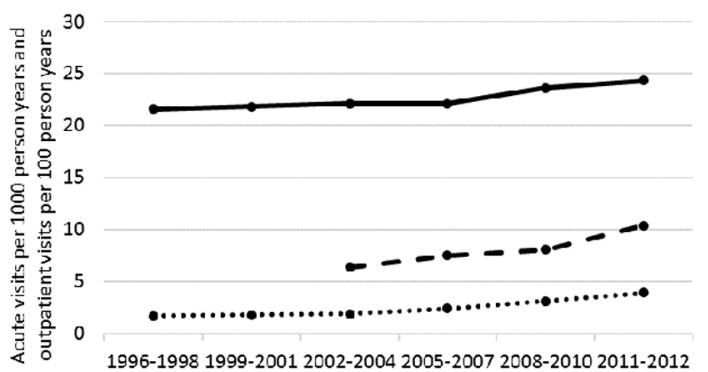

Long-term Residents

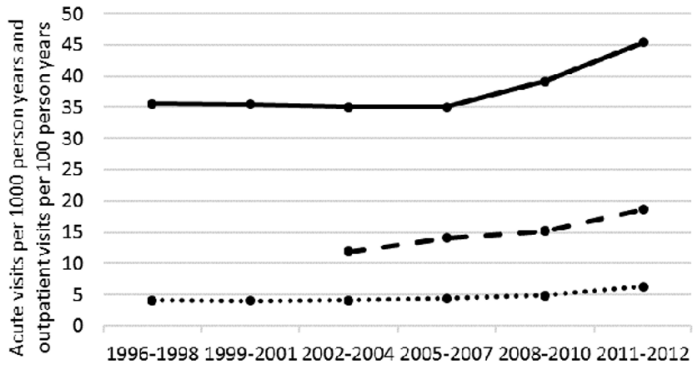

1996-1998 1999-2001 2002-2004 2005-2007 2008-2010 2011-2012 understand why these service differences exist to ensure recent immigrants in need of mental health services are identified and able to access needed care. Understanding whether divergent trends reflect difficulty accessing physician mental healthcare or whether alternative models of mental health service delivery are serving these populations is important. Development of strategies to reduce potential inequities in access and use with an active effort to clarify the role of mental health services for recent recent immigrant populations, despite an increased acute care service use over time. Future studies are needed to 
immigrants are essential to ensuring equity in the provision of mental health service for all youth.

\section{Author affiliations}

${ }^{1}$ Hospital for Sick Children, Toronto, Ontario, Canada

${ }^{2}$ Department of Pediatrics, University of Toronto, Toronto, Ontario, Canada

${ }^{3}$ Institute for Clinical Evaluative Sciences, Toronto, Ontario, Canada

${ }^{4}$ Child Health Evaluative Sciences, Sickkids Research Institute, Toronto, Ontario,

Canada

${ }^{5}$ Institute of Health Policy, Management and Evaluation, Dalla Lana School of Public

Health, The University of Toronto, Toronto, Ontario, Canada

${ }^{6}$ Centre for Research on Inner City Health, Li Ka Shing Knowledge Institute, St.

Michael's Hospital, Toronto, Ontario, Canada

Contributors NRS conceptualised and designed the study, interpreted the results, drafted the initial manuscript, revised the manuscript and approved the final manuscript as submitted. ML, TAS, MLU and AG conceptualised and designed the study, interpreted the results, revised the manuscript and approved the final manuscript as submitted. HL conceptualised and designed the study, had access to and analysed the data, interpreted the results, revised the manuscript and approved the final manuscript as submitted. All authors approved the final manuscript as submitted and agree to be accountable for all aspects of the work.

Funding This study was supported by the Institute for Clinical Evaluative Sciences (ICES), which is funded by an annual grant from the Ontario Ministry of Health and Long-Term Care (MOHLTC). AG is funded through an Applied Chair in Child Health Services and Policy Research from the Canadian Institutes for Health Research (CIHR). MLU holds a CIHR New Investigator Award. Data cutting for this project and analysis was supported by the Ontario Ministry of Health and Long-Term Care.

Disclaimer The opinions, results and conclusions reported in this paper are those of the authors and are independent from the funding sources. No endorsement by ICES or the Ontario MOHLTC is intended or should be inferred. Parts of this material are based on data and information compiled and provided by the Canadian Institute for Health Information (CIHI) and Immigration, Refugees and Citizenship Canada (IRCC). However, the analyses, conclusions, opinions and statements expressed herein are those of the authors and not necessarily those of $\mathrm{CIHI}$ and IRCC.

Competing interests None declared.

Patient consent Not required.

Ethics approval The study was approved by the Research Ethics Board at Sunnybrook Health Sciences Centre in Toronto, Ontario.

Provenance and peer review Not commissioned; externally peer reviewed.

Data sharing statement The data set from this study is held securely in coded form at the Institute for Clinical Evaluative Sciences (ICES). While data sharing agreements prohibit ICES from making the data set publicly available, access may be granted to those who meet pre-specified criteria for confidential access, available at http://www.ices.on.ca/DAS. In addition, the full dataset creation plan is available from the authors upon request.

Open access This is an open access article distributed in accordance with the Creative Commons Attribution Non Commercial (CC BY-NC 4.0) license, which permits others to distribute, remix, adapt, build upon this work non-commercially, and license their derivative works on different terms, provided the original work is properly cited, appropriate credit is given, any changes made indicated, and the use is non-commercial. See: http://creativecommons.org/licenses/by-nc/4.0/.

\section{REFERENCES}

1. The mental health of children and youth in Ontario: a baseline scorecard. Toronto, ON: Institute for Clinical Evaluative Sciences, 2015.

2. Waddell C, Shepherd CA, Schwartz C, et al; Child and youth mental disorders: prevalence and evidence-based interventions. Vancouver, BC: Children's Health Policy Centre, British Columbia Ministry of Children and Family Development, 2014.

3. Mapelli E, Black T, Doan Q. Trends in pediatric emergency department utilization for mental health-related visits. J Pediatr 2015;167:905-10.

4. Olfson M, Druss BG, Marcus SC. Trends in mental health care among children and adolescents. N Engl J Med 2015;372:2029-38.
5. Beiser M, Goodwill AM, Albanese P, et al. Predictors of immigrant children's mental health in Canada: selection, settlement contingencies, culture, or all of the above? Soc Psychiatry Psychiatr Epidemiol 2014:49:743-56.

6. Beiser M, Zilber N, Simich L, et al. Regional effects on the mental health of immigrant children: results from the New Canadian Children and Youth Study (NCCYS). Health Place 2011;17:822-9.

7. Beiser M, Hou F, Hyman I, et al. Poverty, family process, and the mental health of immigrant children in Canada. Am J Public Health 2002;92:220-7.

8. Immigration and ethnocultural diversity: Key results from the 2016 Census. 2017. https://www150.statcan.gc.ca/n1/daily-quotidien/ 171025/dq171025b-eng.htm (cited 16 August 2018).

9. Government of Canada. Immigration and Refugee Protection Act, 2001.

10. Bragg B. A guide to Canada's changing immigration policy. Calgary, AB: Ethno-Cultural Council of Calgary, 2013.

11. deKeyser L, Svedin CG, Agnafors S, et al. Multi-informant reports of mental health in Swedish-born children of immigrants and children born to non-immigrants - the SESBiC-study. BMC Pediatr 2014;14:95

12. Huang ZJ, Yu SM, Ledsky R. Health status and health service access and use among children in U.S. immigrant families. Am J Public Health 2006;96:634-40.

13. Vollebergh WA, ten Have M, Dekovic M, et al. Mental health in immigrant children in the Netherlands. Soc Psychiatry Psychiatr Epidemiol 2005;40:489-96.

14. Akhtar-Danesh N, Landeen J. Relation between depression and sociodemographic factors. Int J Ment Health Syst 2007;1:4.

15. Lofors J, Ramírez-León V, Sundquist K. Neighbourhood income and anxiety: a study based on random samples of the Swedish population. Eur J Public Health 2006;16:633-9.

16. Fazel M, Reed RV, Panter-Brick C, et al. Mental health of displaced and refugee children resettled in high-income countries: risk and protective factors. Lancet 2012;379:266-82.

17. Cantor-Graae E, Pedersen CB. Full spectrum of psychiatric disorders related to foreign migration: a Danish population-based cohort study. JAMA Psychiatry 2013;70:427-35.

18. Durbin A, Moineddin R, Lin E, et al. Mental health service use by recent immigrants from different world regions and by nonimmigrants in Ontario, Canada: a cross-sectional study. BMC Health Serv Res 2015;15:336.

19. Ivert AK, Merlo J, Svensson R, et al. How are immigrant background and gender associated with the utilisation of psychiatric care among adolescents? Soc Psychiatry Psychiatr Epidemiol 2013;48:693-9.

20. Kwak K, Rudmin F. Adolescent health and adaptation in Canada: examination of gender and age aspects of the healthy immigrant effect. Int J Equity Health 2014;13:103

21. Hansson EK, Tuck A, Lurie S, et al. Rates of mental illness and suicidality in immigrant, refugee, ethnocultural, and racialized groups in Canada: a review of the literature. Can $J$ Psychiatry 2012;57:111-21.

22. Pietrus M. Opening minds interim report. Calgary, AB: Mental Health Commission of Canada, 2013

23. Ontario Health Insurance Act: Ontario Ministry of Health and LongTerm Care. 2015. http://www.ontario.ca/laws/regulation/900552

24. The World Bank Regions 2015. 2015. http://www.worldbank.org/en/ about/annual-report/regions

25. Steele LS, Glazier RH, Lin E, et al. Using administrative data to measure ambulatory mental health service provision in primary care. Med Care 2004;42:960-5.

26. Durbin A, Lin E, Moineddin R, et al. Use of mental health care for nonpsychotic conditions by immigrants in different admission classes and by refugees in Ontario, Canada. Open Med 2014;8:e136.

27. Huang KY, Calzada E, Cheng S, et al. Physical and mental health disparities among young children of Asian immigrants. J Pediatr 2012;160:331-6.

28. Dekeyser L, Svedin CG, Agnafors S, et al. Self-reported mental health in 12-year-old second-generation immigrant children in Sweden. Nord J Psychiatry 2011;65:389-95.

29. Barghadouch A, Kristiansen M, Jervelund SS, et al. Refugee children have fewer contacts to psychiatric healthcare services: an analysis of a subset of refugee children compared to Danish-born peers. Soc Psychiatry Psychiatr Epidemiol 2016;51:1125-36.

30. Kim IH, Carrasco C, Muntaner C, et al. Ethnicity and postmigration health trajectory in new immigrants to Canada. Am J Public Health 2013;103:e96-e104.

31. Durbin A, Moineddin R, Lin E, et al. Examining the relationship between neighbourhood deprivation and mental health service use of immigrants in Ontario, Canada: a cross-sectional study. BMJ Open 2015;5:e006690. 
32. Osypuk TL, Alonso A, Bates LM. Understanding the healthy immigrant effect and cardiovascular disease: looking to big data and beyond. Circulation 2015;132:1522-4.

33. Urquia ML, Frank JW, Glazier RH. From places to flows. International secondary migration and birth outcomes. Soc Sci Med 2010;71:1620-6.

34. Guttmann A, Manuel D, Stukel TA, et al. Immunization coverage among young children of urban immigrant mothers: findings from a universal health care system. Ambul Pediatr 2008;8:205-9.

35. Perera J, Wand T, Bein KJ, et al. Presentations to NSW emergency departments with self-harm, suicidal ideation, or intentional poisoning, 2010-2014. Med J Aust 2018:208:348-53.

36. Government of Ontario. Open minds, healthy minds: Ontario's Comprehensive Mental Health and Addictions Strategy. 2011. http:// www.health.gov.on.ca/en/common/ministry/publications/reports/ mental health2011/mentalhealth.aspx

37. Ontario Ministry of Children and Youth Services. A shared responsitiblity: Ontario's policy framework for child and youth mental health. 2006 http://www.children.gov.on.ca/htdocs/English/topics/ specialneeds/mentalhealth/sharedresponsibility.aspx (cited 13 Nov 2015).

38. Puyat $\mathrm{JH}$. Is the influence of social support on mental health the same for immigrants and non-immigrants? J Immigr Minor Health 2013;15:598-605.

39. Glazier R, Zagorski B, Rayner J. Comparison of primary care models in ontario by demographics, case mix and Emergency Department Use, 2008/09 to 2009/10. ICES Investigative Report. Toronto: Institute for Clinical Evaluative Sciences, 2012. 